\title{
Challenges faced by the stricto sensu graduate programs
}

João Carlos Gomes

Dentist and Rector of the UEPG
$T^{\mathrm{s}}$ he main aim of this report was to specifically describe some of the challenges involved in seeking excellence in the stricto sensu graduate programs. Therefore, without claiming to be an exhaustive investigation of the theme, this work constitutes an analysis of the Brazilian national graduate studies system and, in this context, also provides an overview of the current status of graduate programs in the Brazilian State of Parana. Subsequently, a more specific examination of the graduate program at the State University of Ponta Grossa (UEPG) is undertaken, reporting its history along with the institutional policies adopted to foster these activities. Finally, the report concludes by outlining the Graduate Program in Dentistry of the UEPG.

\section{National graduate studies system}

Describing the Brazilian graduate studies system can be both straight-forward yet complex. Numerous strengths of the system can be cited, such as its advances and achievements, impact in helping consolidate the Universities as centers of knowledge creation, its contribution to Brazilian economic development (e.g. Agribusiness and deep-water oil exploration), in addition to the feat of placing Brazil among the top-ranking countries in world academic output. On the other hand, the complexities of the system render the task of a sole individual performing a broad and comprehensive overview of the Brazilian national graduate studies system virtually unfeasible. Nevertheless, as outlined previously, the purpose of the present overview is not to provide an exhaustive analysis of the national graduate studies system, but rather to approach it in such a way as to ascertain the current status of graduate studies at the UEPG in a broader context and more specifically, to examine the Graduate Program in Dentistry, with special focus on the challenges faced in seeking excellence.

The Brazilian graduate studies system experienced a watershed in terms of regulatory framework, following release of the renowned "Sucupira Report" of 1965, produced by the then Federal Board of Education. The report was named after its author, the Professor Emeritus of the UFRJ, Newton Sucupira (Fapesp journal). Graduate studies in Brazil predate this regulatory milestone but up to that point had been centered on independent initiatives predominantly run by the USP and UFRJ institutions. In 2009, during the commemorations to mark its $75^{\text {th }}$ anniversary, the USP paid homage to its pioneering Doctors, who received their titles in the early 1940s. According to Beiguelman (1997, pg. 34), apud Cury (2005), prior to 1960 "few Brazilian Universities offered graduate courses, and at the time, the Brazilian graduate studies system followed the early French model which led only to the title of Doctor. No Master's qualification was available, and "the title of Doctor, achieved through an overly traditional means, was held only by a select few".

The Sucupira report was commissioned by the then Minister of Education and Culture, Flávio Suplicy de Lacerda (15/4/1964 to 10/6/1966), under the Military Government of Castelo Branco, and requested the Federal Board of Education (CFE) to report on the need for institutionalization and regulation of the graduate courses in Brazilian higher education, in a bid to overcome the prevailing vagueness of these courses (Cury, 2005).

Cury reflected that, "the Sucupira Report organized the system along the lines we still see today. It adopted a flexible framework similar to that used in the United States, which splits graduate studies into two categories - namely, stricto sensu, aimed at academic careers, and lato sensu, for more vocational purposes appli- 
cable to individuals working in corporations and other activities - and defined Masters and PhD categories, without the former being a compulsory pre-requisite for the latter".

The fact that the stricto sensu graduate qualification has been predominantly linked to an academic career may represent one of the unwanted side-effects of the Brazilian graduate studies model defined by the "Sucupira Report". Regrettably, this may also have contributed to a large concentration of doctors in academia, coupled with an extreme shortage of this group of professionals in corporations. Clearly this situation also stems from the blinkered vision of both entrepreneurs and a succession of Brazilian governments, which took decades to realize the importance of innovation for Brazil to truly become an aggressive international competitor in a host of sectors. Generally speaking, in the national corporate sphere, the process is still in its infancy.

It was no coincidence that this initiative was jumpstarted during a then recent military government since, according to Claudio de Moura Castro, President of the CAPES research funding body between 1979 and 1982, "The military sought technological development in the full knowledge that technology would only be achieved through investment in science", obviously allied with the training of researchers within the graduate studies system (Fapesp journal).

Despite being against the military government, the academic community was pragmatic and took advantage of the initiative, understanding the strategic importance of the public boost provided by a determined government for the system to achieve consolidation amid heavy investment. Therefore, according to Cláudio Moura de Castro, "the military government transformed the National Fund of Scientific and Technological Development (FNDCT) into a financial tool to drive research", injecting some US\$ 1.2 billion in the $1970 \mathrm{~s}, 70 \%$ of which was invested in Universities and Institutes and dedicated to the graduate studies field (Fapesp journal).

A good example of the pragmatism of the academic community was the adherence of researchers to the system of appraising graduate courses set up in 1976. The fact that the assessment model was overseen by "peers" undoubtedly positively influenced this acceptance, in spite of the system having been introduced by a military government. Another key aspect that helped boost the popularity of the graduate studies assessment system in Brazil was the association between assessment and funding.

\section{Graduate programs in Paraná}

One aspect which drew attention in CAPES's triennial appraisal report (2007/2009), albeit somewhat expected, was the mean scores of the graduate programs by geographical region. On this front, it was clear that the Southeast had the highest mean score, at 4.34 points, followed by the South with a mean of 4.07 . The remaining regions had much lower mean scores, with the Mid-west for in- stance scoring 3.61 , and the North 3.23 points. This is the most likely explanation why the eligibility requirement of 4 in research bids (such as those by the CNPq research funding body) applied only to the South and Southeast regions.

Incentive measures to reduce regional inequality are certainly important. However, scrutinizing regional figures is insufficient to diagnose the serious problem posed by intra-regional inequality. Brazil is a Federation and thus should strive for equality across states and not only among regions. Indeed, for this reason the state of Espírito Santo is not considered part of the Southeast in many Federal bids, since it bears no comparison to the states of São Paulo, Rio de Janeiro and Minas Gerais.

The assessment figures show that it is incongruent to group Paraná together with the most developed states in terms of graduate studies systems in the South and Southeast. This becomes evident upon comparing the mean scores of the programs for the different states: São Paulo (4.53), Rio de Janeiro (4.38), Rio Grande do Sul (4.32), Minas Gerais (4.12), Santa Catarina (4.07) and Paraná (3.85). Another feature of Paraná that strongly differentiates it from the other Southern states is the absence of programs rated with the maximum score of 7 points. In fact, only three programs in the region attained a score of 6, two of which were run at the UEM and the other at the UFPR. Therefore, analyzed from the standpoint of excellence, only $1.6 \%$ of Paranás programs have courses scoring 6 or 7 , a figure which ranks it among the lowest ratings not just in the South or Southeast but in the country as a whole.

Another notable finding was the high percentage of courses scoring 3 in Paraná, a factor contributing significantly to the overall mean score of less than 4 . Therefore, bids such as 027-2007 of the CNPq which stipulated an eligibility criterion of a score of at least 4, are cause for concern. For example, at the time the cited bid was run, the advisors linked to $60 \%$ of the engineering programs in Paraná state were ineligible, and were unable even to apply for scholarships in this bid from the MCT/CNPq, regardless if they were already productivity scholarship holders of the CNPq itself.

On this point, it is important to underscore the forwardlooking policy adopted by the CAPES. Between 2009 and 2011 , there was a $42 \%$ increase in the number of Masters scholarships given in the Southern region, representing a rise from 3911 to 5540 scholarship holders. Nevertheless, in pursuing a policy of incorporation and incentive for new courses, the overwhelming majority of which commence with a score of 3, the growth in the number of scholarships given to institutions with more recent graduate departments has been greater than average. In the case of the UEPG, over the same period spanning from 2009 to 2011, the increase in the number of Masters scholarships was $66 \%$. Taking into account the series of recent scholarships given in May 2011, the number of Masters scholarships from CAPES within our institution has increased by $106 \%$ overall. It is 
worth noting that under the model of new concession of scholarships recently adopted by the CAPES, the merit of programs whose ranking has evolved is also recognized. In other words, the model encompasses mechanisms of both inclusion and stimulus to improve ranking in the triennial assessments. It is hoped that other major funding agencies such as CNPq can follow suit by adopting similar models in their new administrations, contributing together with the CAPES to reduce the asymmetry present in the Brazilian national graduate studies system.

\section{Graduate studies experience at the UEPG}

The State University of Ponta Grossa was created by State Law No. $n^{\circ}$ 6.034, of 06 November, 1969. However, only in the early 1990 s, recognizing the need to evolve by consolidating its position of local leadership as a University, expanding its area of influence, and moving to stay abreast of the new challenges for outstanding institutions of higher education, the University of Ponta Grossa decided to:

a. invest heavily in training teaching staff;

b. take firm steps toward implementing and consolidating the stricto sensu graduate qualification.

It should be emphasized that this policy of qualifying teachers and implementation of stricto sensu graduate courses has also had positive repercussions on undergraduate education and led to infra-structure improvements, through approval of projects by the funding agencies, including the FINEP, CNPq and the Araucária Foundation.

We are proud of the results achieved from strategic planning, considering that before stricto sensu graduate courses can be implemented, they must first be approved by the CAPES. This approval entails a thorough and detailed analysis process, which has become a respected reference model globally. We can now claim to have learned the path, fraught with obstacles, toward implementation and consolidation of the stricto sensu programs, all of which were devised after assessing the strengths and priorities of our institution.

However, in spite of the planning and sharing of experiences with other Universities, the first Masters courses were marked by difficulties and doubts. These problems arose chiefly because the framework for devising stricto sensu programs at the time was not as consolidated as it is today. During the initial implementation period, it was commonplace for Brazilian Universities to adopt the same approach used in undergraduate courses, whereby the course was created first and its ratification subsequently sought by the CAPES. This was the case for the first three Masters courses implemented at the UEPG.

The Institutional Development Plan (PDI) and Institutional Pedagogic Plan (PPI) of the UEPG, in place between 2008 and 2012, represented an important milestone in formalizing the great watershed in the history of a new University boasting a prominent Graduate Department.
As outlined earlier, the UEPG marked its $40^{\text {th }}$ anniversary in 2009. During the first two decades (1970 s and 1980s), its activities were focused on undergraduate work whereas in the third decade (1990s), envisaging a shift in profile, strong incentives to train teaching staff to PhD level were put in place. The period also saw the formal commencement of the Institutional Program of Scientific Initiation Scholarships. Against this background, the UEPG was included in the PIBIC-CNPq program in 1992.

Over the last decade (2000), especially the latter half, an extensive expansion in stricto sensu graduate activities took place. The history of the stricto sensu graduate studies area at the UEPG is therefore relatively recent, yet substantial progress has been made. Currently running some 20 courses (Masters and PhD), the Graduate Department is no longer an isolated entity comprising a few groups, but instead has strong institutional visibility in that it offers graduate programs covering all Knowledge Sectors at the UEPG.

\section{Graduate program in Dentistry at the UEPG}

Implemented in 2003, the program was the first in the Dentistry Area in a public University within Paraná state, and was created based on the following principles:

- Interdisciplinarity - grounded in partnerships with other areas such as Materials Engineering, Chemistry, Physics, Pharmacy and Education.

- International nature - from the first intake of the Masters program, the course has regularly included students from Latin America. Over its 10-year existence, a total of 20 students from other Latin American countries (Argentina, Chile, Colombia, Peru, Venezuela, the Dominican Republic and Ecuador) have been qualified or are currently being qualified.

- Tight integration between graduate and undergraduate areas - this integration has remained a major goal from the outset, through physical proximity, strong participation of its teaching staff in advising scientific initiation students, the co-advising of scientific initiation students by those reading for Masters and $\mathrm{PhDs}$, and the explicit emphasis placed on training, not only of researchers but also lecturers supported by the Didactics discipline.

In 2009, the PhD in Dentistry was implemented at the UEPG, and through the dedication and responsibility of our lecturers and students, the goal has been set to attain a score of 5 on the upcoming Triennial Appraisal by the CAPES (2010/2012).

Finally, we should acknowledge that the UEPG undergraduate course in Dentistry, consolidated and enjoying considerable local, regional and national prestige, evident from the results on the Enade/MEC (numbering among the 3 Dentistry courses in Brazil scoring 5 on the ENADE Ministry of Education Assessment), constitutes an excellent platform for promoting the graduate program in Dentistry. 